\title{
O lirismo de Drummond em "A flor e a náusea"
}

\section{Izandra Alves*}

\begin{abstract}
Resumo: Em meio a tantas proibições, injustiças, mandos e desmandos vistos e vividos na primeira metade do século XX, surge o lirismo de Carlos Drummond de Andrade como forma de questionamento, de filosofia, de protesto, de repensar crenças, valores e conceitos pré-determinados por uma sociedade injusta e excludente. É esse lirismo que permite a reflexão sobre o mundo e, principalmente, do estar no mundo. Drummond é o poeta do nosso tempo. Ele representa ainda hoje a tranqüila maneira de debochar, ironizar e brincar com os problemas e crises da sociedade. Seu forte engajamento social e sua preocupação com a humanidade nos aproxima através dos tempos, conforme revela o poema "A flor e a náusea", do livro A rosa do povo, de 1945. Nesse texto há o reflexo de um poeta maduro, capaz de ver o mundo sob aspectos não vistos e nem refletidos pela maioria dos poetas da época o que colabora para sua consagração como um dos maiores e melhores de todos os tempos.
\end{abstract}

Palavras-chave: poesia; lirismo; sociedade.

\begin{abstract}
Among so many prohibitions, injustices, commands and abuses seen and experienced at the beginning of the last century, Carlos Drummond de Andrade's lyricism appears as a way of inquiry, of philosophy, of protest, of reconsidering beliefs, values and concepts predetermined by an unfair and segregating society. This lyricism is what allows the thinking about the world and mainly the thinking about being in the world. Drummond is the poet of our time. $\mathrm{He}$ still represents today the peaceful manner of mocking, being sarcastic and joking about society's problems and crisis. His strong social commitment and his concern for humankind gather people along the times, as shown in the poem "A flor e a náusea", from the book A Rosa do Povo, 1945. There is in this text the imprint of a mature artist, capable of seeing the world through aspects not seen nor thought of by most of his contemporaries, what contributes for acclaiming him as one of the best and greatest poets of all times.
\end{abstract}

Keywords: poetry; lyricism; society.

A poesia de Carlos Drummond de Andrade enquadra-se no período, entre 1930 a 1945, denominado Segunda Geração Modernista. Esse é o momento de afirmação e desenvolvimento das características marcantes da primeira fase, que tinha como metas a invenção rítmica, o verso livre, o humor, a paródia, temas cotidianos, o coloquialismo, dentre outros. Esta nova fase, então, amplia a temática já trabalhada fazendo também a diversificação das tendências de estilo que vieram a influenciar o perfil contemporâneo. Com um estilo misto ou mesclado, os poetas e escritores dessa segunda geração combinam o elevado e o banal, o grave e o grotesco dentro de suas obras e composições em geral, marcando assim o estilo modernista de ser.

\footnotetext{
* Izandra Alves é mestre em Estudos Literários pela Universidade de Passo Fundo.
} 
Pode-se destacar também neste momento, a preocupação existencial, a exploração de temas como o tempo, o amor e a morte, até então não muito aprofundados, pois não se encaixam na fase combativa, demolidora e destruidora que a antecedeu. Agora é o momento do lirismo vir à tona nos versos dos poetas mais representativos do período como forma de reflexão do mundo e das coisas.

Vive-se num momento de proibições, ditadura e exclusões. No entanto, os poetas dessa fase não se importam com isso; envolvem-se na problemática social, denunciando e revoltando-se contra este sistema, e, de certa forma, demonstrando na própria obra a sua esperança utópica socialista. Não se pode deixar de citar esse período como sendo também um momento de reflexão do próprio fazer poético, época em que começa a afirmar-se a metalinguagem como um dos grandes temas das produções literárias do século XX.

E é nesse contexto social, político e cultural que está inserido Carlos Drummond de Andrade, poeta mineiro tido como um dos melhores da contemporaneidade. Nasceu em 1902, em Itabira, Minas Gerais. Começa sua produção literária aos dezoito anos de idade e continua compondo até quase o fim de sua vida. Sua produção poética é muito extensa e de grande valor literário. $\mathrm{O}$ autor publicou várias coletâneas de poesias e também volumes em prosa que, segundo o pesquisador Francisco Achcar, "embora lúcida e penetrante, não tem a inventividade e a tensão de sua poesia; é amena, agradável, apreciada pelo humor, elegância e agudeza" (ACHCAR, 1993, p.13). Isso revela, então, uma diferença marcante entre sua poesia e sua prosa, pois enquanto a primeira se mostra, em muitos casos, combativa e revolucionária, a segunda é leve, calma e tranqüila.

Na Antologia Poética, publicada em 1962, o próprio Drummond classifica tematicamente sua obra distribuindo os poemas de acordo com o que ele julga que seja o enquadramento perfeito de sua poesia. Diante disso, Achcar (1993) organiza esse agrupamento temático composto por nove itens. São eles:

a) o indivíduo - os poemas desta seção exprimem a visão que o autor tem de si como ser humano e como artista: "um eu todo retorcido" (ACHCAR, 1993, p.14);

b) a terra natal - uma série de poemas enfocam a região em que nasceu. Nas primeiras obras ele a descreve de maneira simples, fotografando os fatos. Trata-se da profunda, complicada e, por vezes, triste relação com o lugar de onde ele provém, pois mesmo que o indivíduo tenha abandonado este lugar, o lugar não o abandona.

c) a família - ligado à infância e à terra natal, o sentimento em relação à família é importante para a compreensão da poesia de Drummond. Não se trata apenas de recordar os parentes, mas de aprofundar o enraizamento do indivíduo na família. Sem qualquer lirismo 
exagerado, questiona "a realidade da família que existe nele, em seu corpo, que é parte de suas emoções e de seu imaginário" (ACHCAR, 1993, p.14);

d) a tentativa de uma visão da existência - esses poemas expressam idéias gerais acerca do mundo e da vida. Essas idéias nascem do momento vivido pelo poeta. Partem da vivência concreta do autor. São questões e conjecturas sobre a existência, sobre o ser e o estar no mundo;

e) o conhecimento amoroso - percebe-se nessas produções a vivência do amor amargo, que é nada romântico ou sentimental;

f) a natureza e função da poesia - a criação poética, as dificuldades de expressão que o poeta encontra estão refletidas nesses poemas; há, ainda, o questionamento sobre o porquê e o como da poesia;

g) os exercícios lúdicos - em muitos dos poemas que abordam essa temática, há uma extrema complexidade por causa dos jogos que o poeta faz com as palavras e da organização sintática do poema, por vezes, com aparência simples e infantil, mas muito mais profundos e reflexivos.

Com base num estudo sistemático sobre a poesia de Carlos Drummond de Andrade percebe-se que sua obra não é um amontoado de temas e assuntos, como possa parecer. Isso porque tópicos como: ironia, família, terra natal, destruição, repetição, cromatismo, província, máquina do mundo, "gauche" e tantos outros, só podem ser entendidos devidamente quando postos num jogo de correlação. Tais temas, aparentemente distintos, são interligados quando vistos e analisados sob um mesmo plano, e não separados ou fragmentados.

Longe de ser apenas um dos temas em profusão na obra de Carlos Drummond de Andrade, o tempo é a coordenada a partir da qual se podem reagenciar os tópicos principais de sua poesia, demonstrando o caráter sistêmico de sua construção poética. Para tanto, propõe-se aqui a realização de uma breve explanação sobre uma das inclinações do lirismo drummondiano, a social, que tem em A Rosa do Povo sua representação. Publicado em 1945, é um grande marco na produção de Drummond, pois é com essa obra que o poeta atinge sua maturidade poética que vem se formando desde sua estréia literária. É com essa obra que Drummond atinge o equilíbrio tão esperado, pois resgata preocupações anteriores ao mesmo tempo em que se envolve no cotidiano e na problemática social. A essa altura, sua poesia converteu-se numa sistematização da memória, numa maneira de se reunir através do tempo. $\mathrm{O}$ sujeito, que vinha interagindo com o objeto, agora se interpenetra com ele, e, como conseqüência, alcança o equilíbrio. 
A partir dessa reflexão e, ainda, dialogando com o pesquisador José Guilherme Merquior (1975), pode-se compreender melhor a idéia dos modelos parciais da extensa produção do autor armados em três momentos que se completam: EU maior MUNDO, de Alguma Poesia, EU menor MUNDO, de Sentimento do Mundo, e EU igual MUNDO, de A Rosa do Povo. Essas comparações e associações permitem perceber o grau de envolvimento e inclusão do sujeito com o que está a sua volta.

Essa referida identificação entre sujeito e objeto tão bem representada no livro de poemas A Rosa do Povo só é melhor compreendida quando analisado, a fundo, o contexto social e político no qual a obra foi escrita. Vivia-se num período de ditadura (Ditadura Vargas 1930-1945) onde não se permitiam manifestações de qualquer natureza, muito menos as socialistas. É assim que Carlos Drummond de Andrade, um anarquista assumido, mostra a realidade do "mundo" e os anseios do "eu", por intermédio da poesia.

Já no título do livro, surge uma palavra de muita significação para a época. A "rosa" aí colocada nos remete à forma visível da bomba atômica que arrasou Hiroshima neste mesmo ano. Esta "rosa" que arrasa e destrói, o faz com a esperança de que o que vier depois dela seja algo puro, inovador, e, acima de tudo, fiel ao que se propõe defender: o povo; "rosa", que também representa a afirmação erótica da vida transposta em poema. Esta mesma "rosa" é o símbolo do socialismo tão proclamado e defendido pelo poeta. Ela designa, segundo Chevalier (2000), uma perfeição acabada, uma realização sem defeito. Simboliza a taça de vida, a alma, o coração, o amor. Por sua relação com o sangue derramado, parece ser freqüentemente o símbolo de um renascimento místico.

Ainda sobre a imagem mística da rosa, não se pode deixar de associá-la à cruz, pois de acordo com a iconografia cristã, conforme Chevalier (2000), o emblema da rosa-cruz pode ser colocado no centro da cruz, ou seja, próximo do coração de Jesus. Tal associação é feita, devido ao fato de que segundo a tradição judaico-cristã, ao pé da cruz de Jesus Cristo nasceu uma rosa, regada, portanto, pelo seu sangue. A rosa passa então a ser o símbolo do sacrifício e do Novo Mundo, pois num lugar de morte, dor e sofrimento, nasceu a VIDA, simbolizada por ela.

Carlos Drummond de Andrade aproxima, nesse livro, seus ideais revolucionários, socialistas e anticapitalistas, com a sua produção literária. Essa obra é, de acordo com Achcar (1993), a mais extensa e variada de todas; são cinqüenta e cinco poemas. Nela se encontram os principais temas de sua obra. Além disso, é relevante a observar a construção, pois o verso livre e a estrofação irregular se alternam com versos de métrica tradicional dispostos em estrofes regulares. O estilo usado pelo autor ora é puro, ora é mesclado, o que causa grandes 
discussões entre os críticos da literatura moderna. No entanto é um dos mais apreciados e valorizados do período por causa de sua linguagem marcante, com características modernistas.

É nesta produção que se percebe o sentido de destruição, que não é apenas evidente, mas que se apresenta como contrapeso da própria vida. Cerca de vinte e três poemas entre os cinqüenta e cinco deste livro, tratam reincidentemente da destruição. Aí está a vida partida, repartida, triturada, cortada, dissipada, fluindo e refluindo pelos subterrâneos, pelas ruas, numa multidão de formas, viajando entre a sombra e a luz.

Diante disso, não há de se estranhar que na expansão da consciência temporal viesse inserido o germe da destruição, que compromete e impulsiona a consciência em trânsito. Para exemplificar esse clima de corrosão é necessário dizer que o livro foi escrito durante os anos da Segunda Guerra Mundial. O alvorecer da consciência temporal do autor coincide com o arrasar das cidades e homens nos campos de concentração. Existe uma batalha que se trava corpo a corpo, noticiada pelos jornais, e ela não é senão o prolongamento de uma outra, contínua e surda, do Ser contra o tempo.

Incluído no livro que é o objeto de estudo deste trabalho, está o poema "A Flor e a Náusea" que representa a explosão revoltada do indivíduo diante do mundo em que vive ao mesmo tempo em que mostra a esperança quando do aparecimento de uma flor que perturba. É através de um passeio pela rua cinzenta que o sujeito depara-se com a náusea; vê-se enjoado e tem o desejo de vomitar sobre tudo o que lhe incomoda e perturba. No entanto, nem tudo está perdido, pois é desse enjôo, revolta, náusea e ódio que brota uma flor feia, que nem se consegue classificar, mas que fura o asfalto. Isso acontece ao mesmo tempo em que parece armar-se uma tempestade, que é símbolo de uma violenta perturbação na ordem desse tempo de nojos, enjôos e vômitos.

A flor, que faz parte do título do poema e também do livro onde o mesmo está inserido, simboliza, de acordo com Chevalier (2000), a imagem das virtudes da alma, é o símbolo do amor e da harmonia que caracterizam a natureza primordial; ela se identifica ao simbolismo da infância e, de certo modo, ao estado edênico. É também, pelo contexto da época, a manifestação da arte espontânea, sem artifícios e, no entanto, perfeita. A náusea, em contrapartida, é o enjôo, o asco, o nojo. Conforme escritos de Achcar (1993), em sentido psicológico, a náusea é uma palavra do vocabulário existencialista da época (título de um romance do filósofo francês Jean-Paul Sartre, um dos pais do existencialismo).

Nota-se que Drummond aproxima duas palavras distintas semanticamente o que causa no leitor, à primeira vista, um grande impacto. "Flor e Náusea" juntas: o nascer e a perfeição, 
unindo-se ao nojo, à destruição e à repugnância. A aproximação deste oxímoro permite ao leitor criar um universo literário que o identifique com esse mundo e abra possibilidades para que transite livremente por ele, percebendo através das metáforas e demais figuras que o constitui, o reflexo da sociedade em que está inserido.

Para melhor ilustrar o que já fora dito sobre o poema, faz-se necessário observar mais atentamente alguns aspectos de sua composição:

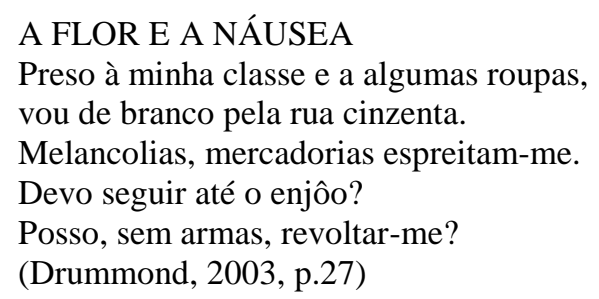

Nota-se aqui a riqueza de sentido no que diz respeito à enumeração do que é abstrato e concreto, geral e particular, pois a classe social e as roupas são o que prendem o sujeito ao mundo e, ao mesmo tempo, o caracterizam de maneira extremamente econômica e abrangente. Também se percebe a relação com a sua classe profissional. Ele é um poeta que deve restaurar o vínculo com a sociedade sem esquecer que é um poeta, pois a participação social se dá pela poesia, através da linguagem poética. Pode-se entender esse indivíduo como alguém descompromissado com a realidade, pois no momento em que sente o enjôo, sente por estar isolado da sociedade e procura buscar uma conexão com o coletivo.

Há a presença da antítese das cores (branco - cinzento), que faz ressaltar, através do contraste, a diferença e o isolamento do sujeito no sombrio mundo que o cerca. Através da paranomásia o poeta aproxima mercadorias e melancolias - o social, concreto e o psicológico, abstrato. Esse jogo de palavras ressalta o desgosto por esse mundo mercantilizado, capitalista, consumista. Ainda é preciso observar o que diz respeito ao extrato fônico dessa estrofe; nota-se a aliteração da letra "m" ao longo dos versos, o que pode remeter a um termo chulo - merda - como forma de demonstrar repugnância e descontentamento.

Cabe observar também a segunda estrofe:

Olhos sujos no relógio da torre:

Não, o tempo não chegou de completa justiça.

O tempo é ainda de fezes, maus poemas, alucinações e espera.

O tempo pobre, o poeta pobre

fundem-se no mesmo impasse.

(Ibid: 27)

Aqui, o olhar é afetado pelo objeto olhado, os olhos parecem contaminados pela sujeira do ambiente. Através da hipálage, que desloca a característica dada à torre e ao relógio, para os olhos. Vê-se que, assim como a rua é poluída e cinzenta, o relógio e a torre 
também são sujos, mas a atribuição do adjetivo é dada aos olhos. Esses adjetivos são também usados para definir o "tempo" em que se estava vivendo ("fezes", "sujos", "maus", "pobres").

No segundo verso desta estrofe há o deslocamento do complemento dado a tempo "de completa justiça" - alterando assim, a construção do verso e constituindo então, um hipérbato. Há ainda a aliteração da letra "p" bem como o paralelismo no terceiro e quarto versos com as palavras "tempo e pobre". Com isso, o tempo social e o tempo individual fundem-se no mesmo drama para colaborar com a inserção do indivíduo em sua época e espaço.

\title{
Lê-se na terceira estrofe:
}

Em vão me tento explicar, os muros são surdos.

Sob a pele das palavras há cifras e códigos.

O sol consola os doentes e não os renova.

As coisas. Que tristes são as coisas consideradas sem ênfase. (Ibid: 27)

No plano fônico, se sobressai a aliteração do "s" unindo-se ao jogo sonoro das palavras SOL e conSOLa. Vê-se que a esperança é pequena (apenas o sol para consolar) para os habitantes desse mundo doente. Há, também, nessa estrofe, outra hipálage: os muros "surdos" substituem as pessoas "surdas como muros". Nesta tentativa de comunicar-se com os muros o poeta ressalta o mais profundo estado de solidão e indiferença das pessoas para com ele. Retoma-se, ainda, no segundo verso, o já citado sobre a época de proibições que se vivia; a linguagem, agora, se torna um perigo constante, onde as palavras escondem "cifras e códigos”, pois podem conter múltiplas significações e sentidos, além de esconder interesses econômicos e códigos secretos. No quarto verso, com a expressão "as coisas", há a figura denominada paralelismo.

A quarta estrofe:

\author{
Vomitar esse tédio sobre a cidade. \\ Quarenta anos e nenhum problema \\ resolvido, sequer colocado. \\ Nenhuma carta escrita nem recebida. \\ Todos os homens voltam para casa. \\ Estão menos livres mas levam jornais \\ E soletram o mundo, sabendo que o perdem. \\ (Ibid: 27)
}

Como é da preferência de Drummond, surgem aqui elementos de linguagem baixa como "vomitar", e os anteriormente empregados "enjôo, fezes e nojo" marcando a mistura de estilos desse poema de tom grave, elevado, voltado para aspectos sérios e problemáticos da vida. Destaca-se também a preocupação com a solidão, pois as pessoas só tomam conhecimento de fatos trazidos pelo jornal, não há diálogo ou correspondências. A metáfora 
do último verso deixa claro que as notícias do mundo, ou sobre o mundo, lhes chegam lenta e friamente, sem maior envolvimento; é um "soletrar".

A quinta estrofe diz:

Crimes da terra, como perdoá-los?

Tomei parte em muitos, outros escondi.

Alguns achei belos, foram publicados.

Crimes suaves, que ajudam a viver.

Ração diária de erro distribuída em casa.

Os ferozes padeiros do mal.

Os ferozes leiteiros do mal.

(Ibid: 27)

No plano sintático, vê-se o paralelismo presente nos dois últimos versos que, no contexto da estrofe, nos remetem às notícias falsas trazidas pelos jornais. Remete ainda aos crimes do mundo (injustiça, má distribuição) que nos envolvem a todos, inclusive ao autor de belos "crimes" que foram publicados, os "crimes suaves que ajudam a viver" - talvez referência a poemas em que Drummond censurava a falta de consciência da injustiça social.

Na sexta estrofe:

Pôr fogo em tudo, inclusive em mim.

Ao menino de 1918 chamavam anarquista.

Porém meu ódio é o melhor de mim.

Com ele me salvo

e dou a poucos uma esperança mínima.

(Ibid: 27)

Há nesta estrofe um paralelismo sonoro com "mim" e a aliteração da letra "m" - em possível associação com o já referido termo vulgar "merda". Já o que chama a atenção no plano semântico é a metáfora do "pôr fogo", ou seja, é preciso purificar-se, rever conceitos e atitudes suas e da sociedade. No segundo verso, o poeta relembra que aos dezesseis anos declarou-se anarquista quando foi expulso do colégio de padres, acusado de insubordinação mental. Com esta declaração, sente-se menos culpado e conivente com a náusea em que vive a sociedade da qual faz parte.

Na sétima estrofe:

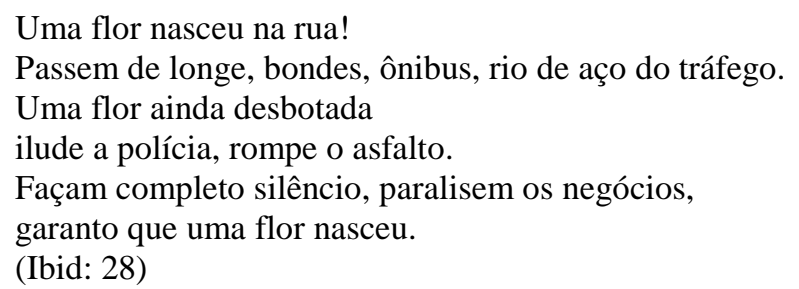

A metáfora no segundo verso - "rio de aço do tráfego" - refere-se ao desenvolvimento e crescimento das cidades, fazendo com que o trânsito torne-se intenso e cada vez mais acelerado, influenciando também na "aceleração da humanidade". Ao transcrever foneticamente a palavra "nasceu” (/N/ /A/ /S/ /E/ /U/) é possível uma associação 
com a "náusea" pois esta pode ser formada a partir do anagrama da palavra nasceu. Com isso, mais se sustenta a idéia de que esta flor perturbadora da ordem e da disciplina surge do nojo, da raiva e da revolta, mas, ao mesmo tempo tem o compromisso de sufocar este ambiente de "podridão" do qual saiu. No quarto verso, percebe-se que a flor que acaba de nascer representa a violenta perturbação da “ordem" estabelecida, pois aparece mesmo sem o consentimento das autoridades. Ela é a própria imagem da poesia e do desabrochar revolucionário.

Na oitava e nona estrofes:

Sua cor não se percebe.

Suas pétalas não se abrem.

Seu nome não está nos livros.

É feia. Mas é realmente uma flor.

Sento-me no chão da capital do país às cinco horas da tarde

e lentamente passo a mão nessa forma insegura.

Do lado das montanhas, nuvens maciças avolumam-se.

Pequenos pontos brancos movem-se no mar, galinhas em pânico.

É feia. Mas é uma flor. Furou o asfalto, o tédio, o nojo e o ódio. (Ibid: 28)

É muito importante nessa estrofe ater-se à aliteração da letra "s", pois agora a flor já nasceu e simboliza a transgressão de normas e a própria revolução, ou ainda o "socialismo" defendido pelo poeta. Há aqui também um paralelismo que relaciona os dois últimos versos das duas estrofes finais do poema - "É feia”. É necessário, no poema, dar ênfase à feiúra da flor, porque a revolução que ela representa não acontece de maneira pacífica e bela, mas sim, requer muita luta, confrontos e desajustes até que a paz e a beleza sejam instauradas para todos. O quarto verso apresenta a metáfora onde "as galinhas em pânico" são sinal de tempestade iminente, e esta, nada mais é do que a grande transformação social que está para acontecer. Pode ainda haver uma referência política na imagem das "galinhas em pânico": os integralistas, que eram um grupo parafascista brasileiro, que pouco antes haviam tentado tomar o poder, eram chamados de "galinhas verdes", por se uniformizarem com camisas dessa cor, inspiradas nas camisas negras dos fascistas italianos e, também, mostravam-se preocupados com a idéia da organização socialista. Por ser a última estrofe do poema, vê-se o êxito do poeta na travessia da náusea com a ajuda da flor, essa forma ainda insegura, mas com uma força incontrolável, a REVOLUÇÃO.

Enfim, é possível notar o grande envolvimento do poeta com o seu tempo. Em A rosa do povo, Drummond usa seu lirismo a fim de ilustrar uma sociedade suja, marcada e doente na qual ele está inserido. O eu lírico expressa seu descontentamento diante do mundo e das pessoas; procura desabafar o sentimento de repulsa por essa sociedade mesquinha e hipócrita. No entanto, nem tudo está perdido, pois há a possibilidade de que do meio de tanta sujeira, 
náusea e enjôo brote a flor perturbadora, ou seja, acredita-se em um futuro melhor, no desabrochar da revolução socialista.

\section{Referências}

ACHCAR, Francisco. A Rosa do Povo \& Claro Enigma. Roteiro de Leitura. São Paulo: Ática, 1993.

ANDRADE, Carlos Drummond de. A rosa do povo. 27 ed. Rio de Janeiro: Record, 2003.

CHEVALIER, Jean. Dicionário de símbolos. 15 ed. Rio de Janeiro: José Olympio, 2000.

D’ONOFRIO, Salvatore. Teoria do texto; teoria da lírica e do drama. São Paulo: Ática, 1995, vol.2.

GOLDSTEIN, Norma. Versos, Sons, Ritmos. 8 ed. São Paulo: Ática, 1994.

MERQUIOR, José Guilherme. Verso universo em Drummond. Rio de Janeiro: José Olympio, 1975.

SECCHIN, Antônio Carlos. Poesia e desordem. Rio de Janeiro: Topbooks, 1996. 